\title{
ON THE CONSTRUCTION OF PROBLEMS AND SOLUTIONS IN THE CLIENT-CONSULTANT RELATIONSHIP
}

\author{
STEFAN HEUSINKVELD \\ Nijmegen School of Management, University of Nijmegen \\ P.O. Box 9108, NL-6500 HK Nijmegen, The Netherlands \\ s.heusinkveld@fm.ru.nl \\ KLAASJAN VISSCHER \\ School of Business, Public Administration and Technology, University of Twente,
}

\begin{abstract}
Consultants play a prominent role in the supply of new and fashionable organization concepts on the market for management solutions, but it is still unclear how they use these concepts in their assignments within client organizations. Drawing on the work of Schön, this study shows that, unlike current conceptualizations, consultants do neither regard the construction of problems and solutions as predetermined by these concepts nor as an entirely unstructured and open-ended effort. More specifically, our analysis identifies several key factors related to the client, the problem situation and the consultant's background that determine the variety of possible routes in the way problems and solutions are constructed during consulting assignments. We believe this has some notable implications for any theoretical treatment of the client-consultant relationship and the role of new concepts and methods in this.
\end{abstract}

\section{INTRODUCTION}

It is well known that consultants play an important role in the production of new organization concepts on the market for management solutions (Abrahamson, 1996; Suddaby \& Greenwood, 2001; Clark \& Fincham, 2002; Sahlin-Andersson \& Engwall, 2002). By propagating these concepts they draw the attention of managers to specific organizational problems and, in relation to these, offer structured approaches to solve these. More recent there has been attention to the way consultants develop a repertoire to support the commercialization and implementation of these concepts (Heusinkveld \& Benders, 2005). An important, but still open question is how consultants use these concepts in their assignments within client organizations. To what extent do these concepts determine the way in which the problem solving process takes shape? Do consultants talk predetermined problems into organizations in order to sell standardized solutions, or can, relatively independent from these concepts the 'therapy' remain open-ended? Theorists have a double message, that is, concepts and methods are particularly useful in the process of problem solving -they can be quite fashionable among managers and consultants- but they should not be applied too rigidly and have to be seen more as a guidance than a religion (Werr, 1999). However, it remains unclear how these concepts are actually applied in praxis. As Werr stated: '...the application of this knowledge is hardly discussed' (2002: 104).

In this paper we further explore how problems and solutions are shaped in the context of a client-consultant relationship and the way organization concepts are used in this process. As a starting point, we draw on the work of Schön $(1983,1987)$ because it provides us with important 
insights into how problem-solving processes are perceived in organizational praxis. Specifically, we will discuss the key concepts of framing and naming which have, at least to our knowledge, been ignored in literature about the client-consultant relationship. Using sixty-four in-depth interviews, this paper argues that consultants neither regard the construction of problems and solutions in a client organization as predetermined by fashionable organization concepts, nor as an entirely unstructured and open-ended effort, but as something that takes shape during the process. More specifically, our analysis identifies several key elements related to the client, the design situation and the consultant's background that influence the variety of possible more or less predetermined routes in an assignment. As we will argue in the paper, this has some notable implications for any theoretical treatment of the role of new concepts and methods in the clientconsultant relationship.

\section{A SUPPLY OF PROBLEMS AND SOLUTIONS}

Organizations have always been confronted with a supply of different organizational problems (Lammers, 1988; Brunsson \& Olsen, 1997). The persistence of these problems offers a fertile ground for constantly introducing new and promising solutions. Management consultants increasingly occupy a prominent position on the market for these solutions (Clark \& Fincham, 2002; Faust, 2002). With this they are determining what in this market is seen as relevant problems and legitimate solutions (Abrahamson, 1996; Kieser, 1997). Critical approaches of management consultancies tend to argue that consultants seek to talk problems into organizations in order to sell their solutions and thereby increase their business (Staute, 1996; O'Shea \& Madigan, 1997; Pinault, 2000; Kieser, 2002). Kieser even argued that 'consultants who compile a new management concept also construct the business problem for which the offered solution fits' (Kieser, 2002: 180). This strand of work particularly focuses attention to the rhetorical strategies used by consultants and shows how managers are seduced to accept the problems and adopt the solutions proposed by these knowledge suppliers.

In contrast to the previous approaches, research concentrating on the organizational context within which the client-consultant relationship takes shape indicates that the construction and implementation of solutions in a client organization is not particularly unproblematic for consultants (Pettigrew, 1975; Bloomfield \& Danieli, 1995; Sturdy, 1997; Werr \& Styhre, 2002; Wright, 2002). It is argued that not only the consultant determines the way problem solving processes develop, but particularly the client plays a major role in what is seen as a relevant problem and how the 'therapy' takes shape. Congruent to the interaction between manager and guru in which: 'meanings and identities are produced and consumed through the interaction between guru and client' (Clark \& Salaman, 1998: 46), both consultants and managers are regarded as reflective and critical participants in the process within which problem situations and solutions are constructed and re-constructed. Such a more interactive view of the relationship between knowledge supplier and consumer feeds the idea that the client-consultant relationship should be regarded as open-ended, thereby 'containing no ex-ante structures' (Fincham, 1999). The client is not necessarily a victim of the consultancy rhetoric and the consultant is not a priori left at the mercy of the client's whimsicality and restricted by the client's demands. Such a view easily presents each problem solving process as unique, amorphous and highly unpredictable.

Structured methods allow consultants to stimulate communication thereby reducing a client's and their own uncertainty about the trajectory in the problem solving process (Werr, 1999). These codified approaches are seen as a cognitive support to consultants in the advice 
process by offering a framework that will guide their actions through the 'swampy' praxis. At the same time it is emphasized that methods do not directly shape the actions of consultants, rather it is 'improvisation' characterizes consultancy work (Visscher \& Rip, 1999; Morris, 2001). Improvisation on methods is necessary to come to the 'real' problem and develop tailor-made solutions. In much prescriptive literature on consulting it is argued that consultants should have some kind of model to prevent them to 'drown' in an information overload at the start of an assignment, but at the same time it is stressed that they should not rigidly stick to this model and listen well to the client (Greiner \& Metzger, 1983; Holtz, 1983; Nathans, 1991; Vrakking \& Cozijnsen, 1994). Improvisation in the application of methods is not only considered necessary to develop tailor-made solutions but also to feed the internal knowledge system (Werr \& Stjernberg, 2003). Or as Werr, et al. put it: ' ...it is in the process of translating a method's abstract concepts to a specific situation that learning takes place' (1997: 306). However it is still unclear how exactly consultants construct these variations when they perform their assignments.

\section{FRAMING AND NAMING}

As a starting point for further exploring the role of new concepts in the way in which problems and solutions are constructed in the client-consultant relationship, we draw on the work of Donald Schön $(1983,1987)$. This work provides us with important insights into how problemsolving processes are perceived in organizational praxis. Specifically, we will discuss the key concepts of framing and naming, which have, at least to our knowledge, been ignored in literature about the client-consultant relationship.

One of Schön's central concepts is 'framing'. This is putting a 'frame' - a model, a concept, or a point of view - on a problem situation, thus creating a starting point for the problem-solving process. In Schön's view, this frame is or should be a hypothesis, a 'what if', on the basis of which a situation can be further explored in terms of its consequences and necessary conditions. Within a chosen frame, one 'makes moves', exploring and evaluating in terms of the desirability of consequences, consistency with earlier moves, and appreciation of created problems and potentials. When one gets stuck in a frame, because the consequences prove too unfavorable, or because important conditions cannot be fulfilled, one can reframe the situation by putting a different organizing model or concept on it. A problem solving process is considered 'a game with the situation', making moves and listening to the 'back talk' of the situation in order to explore the situation and confirm or refute the adequacy of the frame.

Intertwined with the concept of framing is the concept of naming (Schön, 1983, 1987). Naming is the recognition of a problem situation as being of a certain kind, and choosing a proper frame for it. According to Schön, it is important to frame situations without reducing them to standard problems. Therefore, naming of the situation should not just be a process of pigeonholing, categorizing it as a certain kind of problem and applying the right method or solution for it. It is a process of 'seeing-as', recognizing a new situation as a variation of a situation that has been encountered before, and 'doing-as', acting in the new situation as in the former situation. This 'seeing-as' is a hypothesis that may prove unproductive in the course of the process; the resulting reframing of the situation then also implies a renaming. 


\section{PROBLEM SOLVING IN THE CLIENT-CONSULTANT RELATIONSHIP}

In this section we discuss the way consultants view the construction of problems and solutions in a client-consultant relationship and the role of popular concepts in this. Central is the question what factors play a role in the extent to which the route of a problem solving process is predetermined? In other words, does the introduction of a concept result in an a priori fixed process and a significant limitation of the options, or can alternative routes remain open? Our analysis of the data shows that various elements can be identified within the process of naming and framing that have important implications for the extent the process of problem solving is regarded as either predetermined or open-ended. First, we concentrate on the starting point of this process: is this regarded as a specific and unique problem of the client or a specific concept or solution. Next, we pay attention to the following exploration and assessment of the situation, as will be argued, two important activities in the process of framing. Finally we go into the different routes and assignment of roles between client and consultant in the process of naming, framing and reframing.

\section{Starting Point: Solution or Problem}

Since consultants are mostly hired as outsiders, the interaction between client and consultant habitually starts with a question articulated by the client. Clients tend to formulate their questions in terms of problems to be solved or in terms of solutions to be realized. In many the projects discussed in the interviews, consultants were hired by clients who said they wanted assistance with the elaboration and implementation of a concept. In some cases the consultant had evoked this question. A number of consultants indicated that their firm publishes books with so-called 'business solutions', persuasive descriptions of generic forms, which are meant to generate a demand for the forms the firm can supply. There are also consultants who point out they do not 'trade in forms'. They tend to dissuade their clients from taking a concept as a starting point and direct their attention to the problems that have to be addressed. None of the interviewed consultants replicated the problems or solutions their clients articulated right away. They all took it as a starting point for further exploration. Consultants apparently assume that the client's question does not necessarily reflect what is really going on.

\section{Exploration: Shortcuts or Detours}

Starting from the possible solutions in the client's question, consultants dig deeper. This digging encompasses the making of an inventory in the organization of alternative ideas about solutions to implement, and of other perspectives on the present problems. The exploration of the problem situation also encompasses an exploration of the organization in which the problem solving process takes place. Consultants need at least a general impression of the organization, firstly to be able to understand the context in which the solutions are articulated, and secondly to form their own opinion of the problems in the organization. The depth of this organizational exploration depends, among other things, on the question for which the consultants are hired, their knowledge of the organization beforehand, the complexity of the design situation, their own methods or habits, and the time-pressure on the project. Possible solutions that are collected in the inventory of forms are not only assessed on their functionality - do they fulfill the functions that need to be realized - but also on their hardness, ambitiousness, and doability. This means 
that consultants judge how difficult it is to elaborate and implement a certain solution, and whether the resources to do so are available in the organization. It is important to make this assessment at the beginning of the problem solving process, because a positive judgment could enable a shortcut in the process, while the negative judgment that a form is too ambitious or too hard to implement would block such a shortcut.

\section{Assessment: Cognitive and Socio-Political Complexity}

The data indicate that the consultants' assessment of the complexity of the problem situation determines for a major part the shape of the problem solving process. The indications of complexity that were mentioned by the interviewed consultants can be divided into two categories: cognitive complexity and socio-political complexity. Cognitive complexity has to do with the difficulty and uniqueness of the situation, the number of levels, the variety of facets, and the size and diversity of the organization. Socio-political complexity has to do with the number of key figures or stakeholders involved, their differences in opinions, perspectives, and interests, and the presence of conflicts and lack of trust among them. Consultants act differently in situations they regard as complex than in situations they regard as simple. They tend to work more carefully, more exploratory, and more reflectively in complex situations. In simple situations, consultants work more straightforwardly and make shortcuts they would otherwise consider rash and risky. The judgment about complexity depends not only on the characteristics of the problem situation, but also on the consultants' experience, expertise, self-confidence, and maybe their brashness or cautiousness. In general, the interviewed consultants warn against regarding a situation as simple too quickly. It may lead to mistakes, and besides, it may repel clients, especially when clients perceive their situation as complex.

\section{Framing and Naming: Between Client and Consultant}

The interviews show that problem situations are framed in a dialogue between consultants and clients. However at the same time, the data indicate that there is much variety in how this dialogue takes place, especially in the division of roles between consultants and clients, and the function of models and concepts. One consultant leaves the framing to the client and refrains from putting his own frame on the situation. In contrast with the previous style, another consultant was not interested in the client's way of framing the situation. He wants to hear concrete stories about what is the matter, and uses his own model to frame the situation. He is like a doctor who wants to hear the patient's complaints in order to make a diagnosis, but is not interested in hearing what the patient himself thinks his ailment is. Various consultants are somewhere in the middle of the styles discussed in the above. Specifically, they discipline gradually, in an exploratory conversation with the client, the situation, and the organization. One of the interviewed consultants stated that he shifts from one frame to another, using a series of models and concepts to try to grasp what is the matter.

The disciplining of a design situation may be the endpoint of a framing process, but not necessarily. In principle, the stability and coherence of the framed situation is precarious, and the exploring, assessing, and disciplining is an ongoing process, which may lead to reframing in the

course of the problem solving process. In many cases consultants reframed the situation as it had been framed by the client in the beginning of the process, and did not reframe their own framing. This reframing constitutes the renaming of the frame that has been put on the situation by the 
client. Only in one case a consultant did have to reframe the situation he had framed himself when the situation proved more complicated than he thought in the beginning. Other consultants also encountered complications and unexpected events during their problem solving processes, but their frame was robust enough to incorporate these.

\section{DISCUSSION AND CONCLUSION}

The aim of this paper is to further explore the role of -popular- organization concepts during the process of problem solving within the context of a client-consultant relationship. In this, particular attention has been given to the process of naming and framing. The analysis of the data shows that organization concepts may play an important role, but these are not readily replicated in a client-consultant relationship. Rather, consultants generally tend to consider a new concept as a possible starting point for further exploring the underlying problems and potential solutions. This is in line with the way Schön $(1983 ; 1987)$ describes the use of frames in the construction of problems and solutions. More specifically, it is argued that a frame initially serves as a hypothesis, a basis for further exploration and assessment. The data analysis reveals different elements related to the client, the consultant and the specific problem situation that determine the possible routes of a problem solving process within a consulting assignment.

This analysis implies that within a client-consultants relationship problems and solutions are neither predetermined by a new concept nor an entirely unstructured, open-ended effort and thereby each problem solving process amorphous and highly unpredictable. The contradiction between concept determined and fully open-ended, as been suggested within current literature is therefore misleading. These situations could only exist if the factors that were identified all point in the same direction. However, the comments of the consultants made clear that even in these extreme situations there would be alternative routes possible. In many cases the relevant factors will not point all in the same direction, will have an influence on each other, and may not have the same significance in different situations. Because of this, the route in the problem solving process will always be determined partly beforehand and partly during the process. This paper showed that concepts do play a role in a client-consultant relationship, but determine the way the problem solving process takes shape only for a limited part. Rather, it is the consultant who may have the possibilities and the ability to let the concept dot its determining work and the way this takes shape mainly crystallizes during the process.

\section{REFERENCES AVAILABLE FROM THE AUTHORS}


Copyright of Academy of Management Proceedings is the property of Academy of Management and its content may not be copied or emailed to multiple sites or posted to a listserv without the copyright holder's express written permission. However, users may print, download, or email articles for individual use. 
Copyright of Academy of Management Proceedings is the property of Academy of Management and its content may not be copied or emailed to multiple sites or posted to a listserv without the copyright holder's express written permission. However, users may print, download, or email articles for individual use. 
Copyright of Academy of Management Annual Meeting Proceedings is the property of Academy of Management and its content may not be copied or emailed to multiple sites or posted to a listserv without the copyright holder's express written permission. However, users may print, download, or email articles for individual use. 